\title{
The Impact of Designed TPACK- Object Based Game on the Performance of JSS 2 Students in Mathematics
}

\author{
Olatoye Mukaila. $A^{1, *}$, Nleya Paul. $\mathbf{T}^{2}$ \\ ${ }^{1}$ University of Botswana, Gaborone \\ ${ }^{2}$ Department of Educational Technology \\ *Corresponding author: mukailaolatoye@yahoo.co.uk
}

Received August 09, 2013; Revised August 01, 2014; Accepted August 07, 2014

\begin{abstract}
This paper sees to the design of Instructional Object Based Game (IOBG) using Technological Pedagogical and Content Knowledge (TPACK) framework and it imparts on the performance of students learning in mathematics as investigated from two sets of subjects. The sample consists of 200 Junior Secondary School 2 (JSS 2) students selected from 20 co- educational schools within Lagos Island and Eti-Osa educational Zones of Lagos State, Nigeria. Multi stage stratified random sampling was used to avoid interclass mixed. 50\% proportionate on each zone and stratified simple random sampling technique was adopted to give non mixed schools within the zones equal chance of being taken. The first sets of subjects were learning in relation to game and performance, while the other set (control group) was treated with Mathematics Achievement Test (MAT) (conventional method). Lessons of 40 minutes on substitution were conducted for the two groups for two weeks, twice per week, which was conducted in each school for 4 weeks in the whole of the two zones. After the lessons the groups were treated with MAT and IOBG, control and experimental groups respectively. A quasi-experimental control group design with repeated measures analysis of covariance was adopted. Two separate summary results of ANCOVA showed that F $(1,199)=$ $12.88 @ \mathrm{p}=0.013$ and $\mathrm{F}(1,193)=13.00 @ \mathrm{p}=0.00$ implied that the use of OBG (game) in teaching and learning had significant effect on the performance of learners in mathematics. Calculated mean scores and 2-way ANCOVA result showed that gender has no significant influence on the performance of learners in either with the used of OBG or MAT.
\end{abstract}

Keywords: instructional game, object based game, TPACK, conventional method, performance, achievement and gender

Cite This Article: Olatoye Mukaila. A, and Nleya Paul. T, "The Impact of Designed TPACK- Object Based Game on the Performance of JSS 2 Students in Mathematics.” American Journal of Educational Research, vol. 2, no. 8 (2014): 674-682. doi: 10.12691/education-2-8-17.

\section{Introduction}

Despite the use of technology for decades to support students' learning in education and despite studies that showed the potential of technology to promote students' learning, many still contend that insufficient data validate the contributions of technology to learning [1]. The results of most studies in game technology were considered too fragmented and unsystematic [8]. The evidence is insufficient that using technology positively affected teaching and learning. Thus, the call continues for more and better empirical evidence of the impact of technology, and Object Based Game (OBG) that are pedagogical structured on academic achievement of learners [7]. The notion of pedagogical content knowledge was first introduced to the field of education as referenced [23] with a group of research colleagues collaborating on the Knowledge Growth in Teaching (KGT) project. The focus of the project was to study a broader perspective model for understanding teaching and learning [25]. The KGT project studied how novice teachers gained new understandings of their own content, and how these new understandings interacted with their teaching. The researchers of the KGT project described pedagogical content knowledge as the knowledge of three knowledge bases coming together to inform teacher practice: subject matter knowledge, pedagogical knowledge, and knowledge of context. Subject matter content knowledge is described as knowledge that is unique to teachers. The view of Shulman as referenced [23] therefore forms the bases of this study.

In a research carried out as referenced [23] where he connected and established empirical support on processes involved in teaching and learning called Pedagogical Content Knowledge (PCK), he focused on the strategies employed in teaching; those strategies that bring about the best learning experience for every learner. PCK involves knowing how to take advantage of different teaching approaches that make a learning experience most suitable for the learners. This includes being flexible and adjusting instruction to account for various learning styles, abilities and interests. Knowing how to best teach a concept so that the learners will receive the best learning experience speaks to the essence of PCK. The different teaching 
approaches employed will vary from teacher to teacher and from differing contexts but invariably will revolve around similar principles for each approach. Reference [10] described pedagogical content knowledge (PCK) as a set of attributes that help someone transfer the knowledge of content to others. Referenced [15] were of the view that the outstanding teacher is not simply a 'teacher,' but rather a 'chemistry teacher,' or an 'English teacher.' While in some sense there are generic teaching skills, many of the pedagogical skills of the outstanding teacher are content specific. Beginning teachers need to learn not just 'how to teach,' but rather mastery of subject matter and the design of instructional materials such as game that facilitate learning as suggested by reference [23].

\subsection{Technological Integration}

The need for technology integration within mathematics teacher preparation and educational programs has also lagged behind expectations [17]. Many scholars in the fields of educational technology and teacher education have extended Shulman's ideas about teacher knowledge by including a third component technological knowledge [13]. Reference [15] shows introduction of the union of these three different types of knowledge as representative of what teachers need to know coining the combined framework "Technological Pedagogical and Content Knowledge” (TPACK). Essentially, TPACK consists of the negotiation of synergy between three forms of knowledge; these are Technological Knowledge (TK),
Pedagogical Knowledge (PK) and Content Knowledge (KC).

Reference [9] defines TPACK as:

...knowledge of the dynamic, transactional negotiation among technology, pedagogy, and content and how that negotiation impacts student learning in a classroom context.

The essential features of TPACK are: (a) the use of appropriate technology (b) in a particular content area (c) as part of a pedagogical strategy (d) within a given educational context (e) to develop students' knowledge of a particular topic or meet an educational objective or student need.

Indeed, TPACK offers the fields of educational technology and teacher education a research framework for guiding pre- and in-service teachers' knowledge assessment and development as well as technology integration in their classrooms [13]. Due to the role of content knowledge in teaching, the call to describe more concretely what TPACK looks like in action and the need to develop assessments to measure and develop TPACK, scholars are beginning to consider TPACK within various content areas such as mathematics and gaming. It is therefore important for instructional media producer to produce or design instructional media using templates like Object Based Game (OBG). This enhances ethical practices that facilitate learning processes with the use of teacher knowledge category as major principles of TPACK being specified in Table 1.

Table 1. Teachers' Professional Knowledge Base Categories [24]

\begin{tabular}{|c|c|}
\hline $\begin{array}{l}\text { Teacher } \\
\text { Knowledge } \\
\text { Category }\end{array}$ & Definition \\
\hline $\begin{array}{l}\text { Subject matter } \\
\text { content } \\
\text { Knowledge }\end{array}$ & $\begin{array}{c}\text { Academic related knowledge Subject matter knowledge includes information or data and the structures, rules, and conventions for } \\
\text { organizing and using information or data. }\end{array}$ \\
\hline $\begin{array}{l}\text { Pedagogical } \\
\text { Content } \\
\text { Knowledge }\end{array}$ & $\begin{array}{l}\text { The combination of content and pedagogy. Information or data that helps lead learners to an understanding would classify as } \\
\text { pedagogical content knowledge. This includes any way of representing a subject that makes it comprehensible to others. }\end{array}$ \\
\hline $\begin{array}{l}\text { Curriculum } \\
\text { Knowledge }\end{array}$ & $\begin{array}{c}\text { Materials and programs that serve as "tools of the trade" for teachers. Knowledge of the curriculum can be considered vertical } \\
\text { (within a discipline area across grades), or horizontal (within grade and across disciplines). }\end{array}$ \\
\hline $\begin{array}{l}\text { General } \\
\text { Pedagogical } \\
\text { Knowledge }\end{array}$ & $\begin{array}{c}\text { Principles of classroom management and organization unrelated to subject matter. General pedagogical knowledge is unrelated to } \\
\text { a specific subject matter and can therefore be implemented in a vast array of classroom settings. }\end{array}$ \\
\hline $\begin{array}{l}\text { Knowledge of } \\
\text { Learners }\end{array}$ & Specific understanding of the learners' characteristics. These characteristics can be used to specialize and adjust instruction \\
\hline $\begin{array}{l}\text { Knowledge of } \\
\text { Educational } \\
\text { Contexts }\end{array}$ & $\begin{array}{l}\text { An understanding of the classroom, the governance and financing of school districts, the character of school communities. } \\
\text { Knowledge of the big picture surrounding the classroom helps to inform teachers about how the community may perceive their } \\
\text { educational actions. This knowledge of educational contexts may also inform teachers about how to proceed in the classroom in } \\
\text { relation to school, community, and state conventions, laws, and rules. }\end{array}$ \\
\hline $\begin{array}{l}\text { Knowledge of } \\
\text { Educational Ends }\end{array}$ & $\begin{array}{c}\text { The purposes and values of education as well as their philosophical and historical grounds. An understanding of the purposes and } \\
\text { values of education will help teachers motivate learners. }\end{array}$ \\
\hline
\end{tabular}




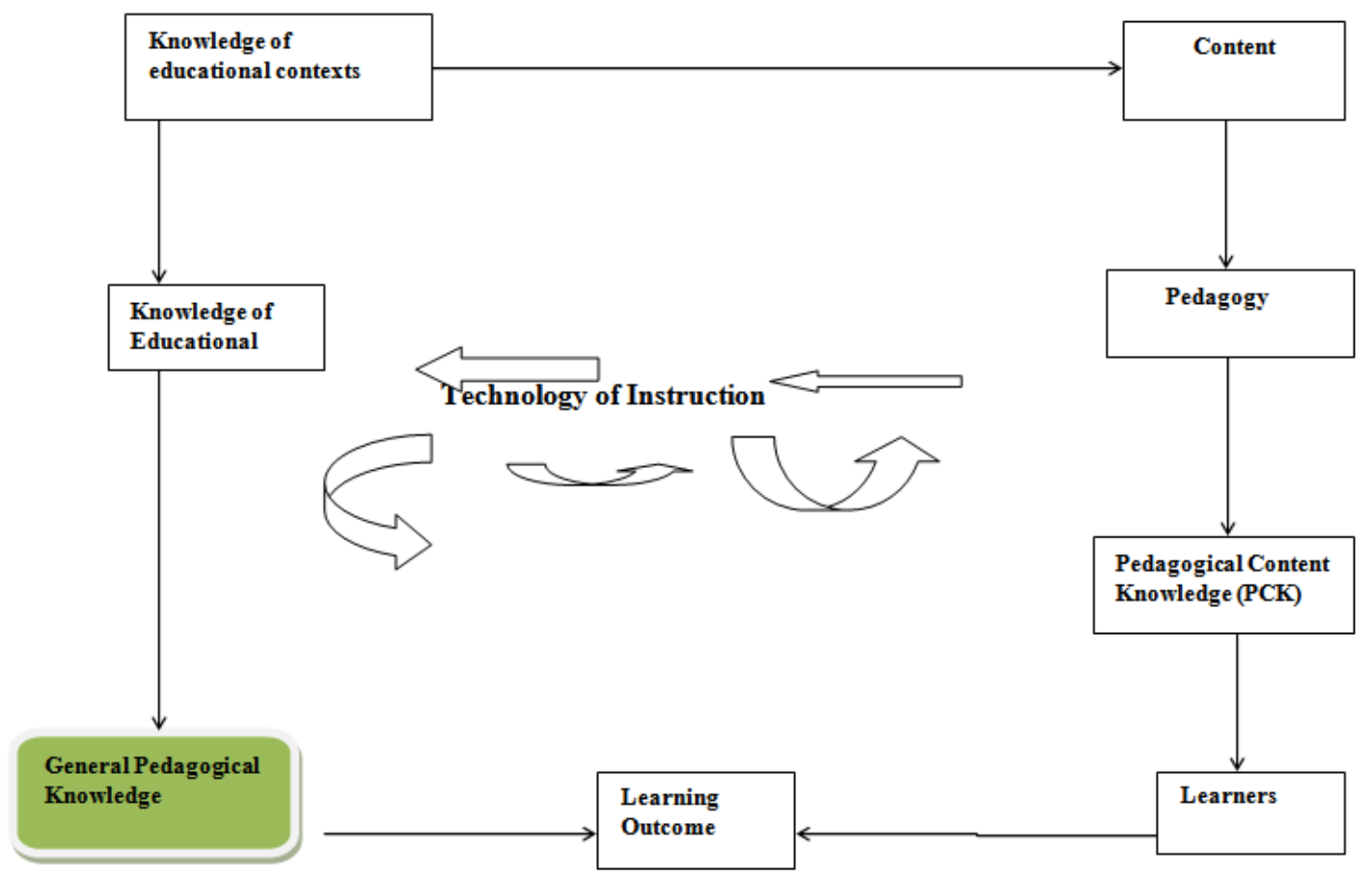

Figure 1. Technology of Instruction (TOI) Model

TOI model in Figure 1 shows that:

(1) Content according to this model consist of subject matter which involves what the instructional diet has within it, to transfer to learners or information seekers yarning to gain from such content. Knowledge of subject matter is technical knowhow on the part of the teacher/ instructor required to transfer content on the subject matter been derived from curriculum.

(2) Pedagogy according to the model is the study of the learning process, study of representation of subject matter and knowledge of content presentation required from teacher.

(3) Pedagogical Content Knowledge involves:

Representation of a subject matter in comprehensive manner

Leading learners to understand curriculum content

Instructional processes (teaching and evaluation of learning process)

(4) General Pedagogical Knowledge involves organisation of instructional diets (what to teach, how to teach and what to use for teaching) or teaching tools (process technologies) and Principle of classroom management.

(5) Knowledge of Educational Contexts involves relationship of school and community that is intercommunication and interaction within the school and among the community in which the school is situated. It also involves proceed in classroom in relation to school.

(6) Knowledge of educational ends include: purposes and values particular curriculum content add to the well being of an individual or group of people to the society and immediate environment and philosophy of education.

(7) Technology of Instruction: involves instrument that facilitate understanding of content to be received by the learners. This is also called motivational tools, teaching aids or instructional transformation these are used to facilitate, motivate and also transform learners' horizon on the learning content.
Object Based Game Technology (OBGT) Design Model

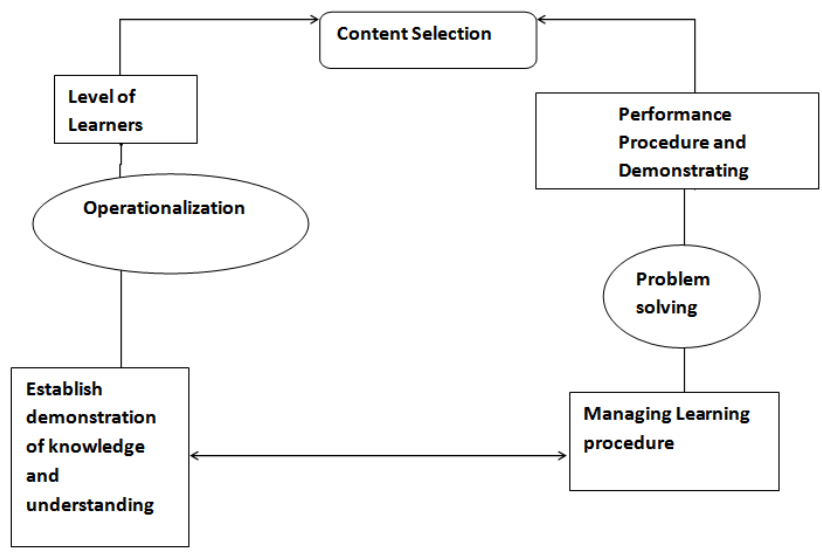

Figure 2. OBGT Model

Figure 2 shows that:

- Content selection in object based game design involves what to teach, objectives the game intends to achieve and Problem to be solved within subject matter drawn from curriculum.

- Level of learners: this involves determining users' level of ability (this involves introducing tasks / problem solving within the mental capacity of the learner), domains of learning (in game design, the designer has to set the rules of the game such that the activities of play affect all the domains of learning) and types of learner (this has to do with i.e. able, or physically challenge learner).

- Performance procedure and demonstration techniques involves design of prototype, test run (pilot testing), and illustration or users' guide on the use of the game.

- Operationalization: this is playing procedure, rules of playing, determination of playing seeds (this include what to be used for playing such as cards). 
- Problem solving: includes problem scenario, operational procedure and review of literature.

- Managing learning procedure involves time management, task and class management.

- Establish demonstration of knowledge and understanding this involves evaluation of content with time frame and establishing range of performance i.e. scoring (Very good, good, fair, bad $=>$ At what points).

Integration of Teachers' Professional Knowledge Base Categories by reference [24] in Table 1 and model of pedagogical reasoning and action as referenced [30] with the reunion of technology as suggested by referenced [15]. Reference [28] view calls for the augmented model called Object Based Game Technological model. This is because teachers' professional knowledge base categories identified by reference [23], is insufficient to handle the present demand of classroom activities. While pedagogical reasoning and action introduced by reference [30] lack technological process to address complexity of classroom activities and game playing.

\section{Research Methodology}

\subsection{OBGT and Mathematics}

Due to the significant roles of content knowledge in teaching, it is needful to describe more concretely the functionality of OBGT, process technologies and the processes involve in the use of adequate teaching technologies look like in action and also develop assessments to measure and develop teaching strategies like OBG. Scholars are beginning to consider technology within various content areas in mathematics [1].

Despite epistemological resistance from teachers with the use of technology in teaching mathematics and slow starts in the field of mathematics education, there may be renewed interest in and even evolving viewpoints toward technology and mathematics [27]. Although the OBGT framework offers a theoretical explanation for teacher knowledge, challenges remain prevalent including the identification of ways to develop, assess, and measure OBGT. Research is now beginning to address these challenges. As reference [14] documented how iterative the development of technology can be in their investigation of college faculty working with master's students in developing online courses. These researchers noted that over the course of the seminar, faculty moved from considering the technology constructs separately toward a more complex understanding of the nuanced interplay of technology construct.

The continued interest in TPACK as an epistemological perspective in the preparation of in- service mathematics and technology teachers and as a knowledge base for infusing game principles, content, and method in the study of technology has yielded a desperate need for mathematics to produce a conceptual framework and taxonomy for the infusion of game upon which future TPACK studies in mathematics and technology education can be based.

\subsection{Analog Game and OBGT Model}

The OBGT model designed in Figure 2 is to provide a framework for the development of analog in educational game development. The model integrated instructional factors proposed by reference [6] and key structural elements of games suggested by reference [22]. The game structure was designed in line with the instructional considerations such as conceptual analysis (content selection, performance procedure and problem solving), instructional strategies (operationalisation of the game, managing learning procedure and establish demonstration of knowledge), and students' strategies (level of learners').

The Game Object Model (GOM) proposed by reference [3], was referred to in developing digital game. The GOM does not provide a framework that links learning theories to game design which OBGT model (Figure 3) does. It (OBGT) contains concrete interfaces to realize the educational objective represented by the abstract interfaces. The Game space embodies all the components (Visualization space, Elements space, and Problem space), Game Achievement (GA) and interfaces (play, exploration, challenges and engagement). The GA and OBGT articulate the process of designing and building educational games, in which the learning objectives are firstly defined to lead the activities, or actions of the game. This was suggested by reference [15], identified as TPACK principles. Each act needs to achieve specific objective(s). The objectives are implemented through the concrete interfaces of the Visualization space, Elements space (graphics, and technology), interaction, gestures and problem space (visual, logic, mathematical, short-term memory and manipulation) to express the abstract interfaces (critical thinking, discovery, goal formation, goal completion and practice) in the Visualization space, and Elements space.

\section{(i) TPACK principles with Object Based Game (OBG)}

Object Based Game Model (OBGM) was initiated by reference [3] to describe a link between the pedagogical dimensions of learning and game elements. The model was adopted to suit the development and design of card games that was framed within TPACK principles. As suggested by reference [4], object based educational games consist of a number of components. These components include: Abstract interface and Concrete interface.

Achievement Game (AG) as suggested by reference [6] \& [15] that TPACK game components include: Visualization space, Element space and Problem space. The suggested components were pulled together to serve as main principles of TPACK adopted for the creation of Substitution Card Games (SCG) used for this study.

\section{(ii) Substitution Card Game using TPACK principles}

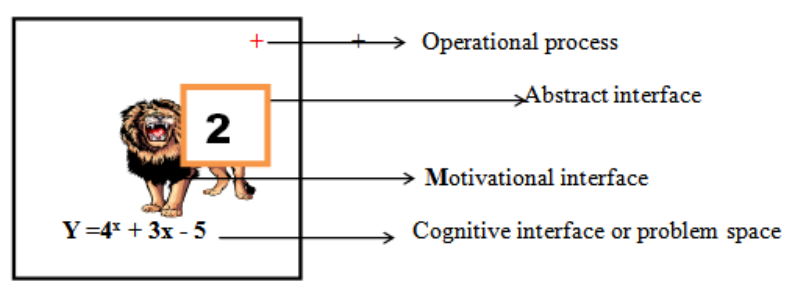

Figure 3. Substitution Card Game using TPACK principles

The game cards were designed in line with TPACK principle that: the card game spaces object include: the 
visualization space and problem objects. These spaces consist of motivational interface, (from Figure 3 the animal represents this interface) challenges and engagement that relate to cognitive activities (such as critical thinking, self discovery, and goal completion). Cognitive interface or problem space is represented by $\mathrm{Y}=$ $4^{x}+3 x-5$ on Figure 3 .

Abstract interfaces refer to all pedagogical and theoretical constructs from Figure 3; 2 (two) that appears on the animal as identified on the abstract interface of the sample card. The card contents area or cognitive levels were structured by using Bloom (1959), taxonomy of knowledge as specified in the table of specification, see Appendix 1 Table A.

\subsection{Gender}

Of all learners' characteristics in relation to computer games and object based games, researchers have been interested in gender differences. Gender differences have been noticed in number ability. According to reference [2] no gender differences are apparent in the early years, but by high school age (approximately 14), males do better at arithmetical reasoning. Also males consistently outperform females on tests of spatial ability; this difference persists from the early grades through high school. It was discovered that men's average scores on the mathematical scale on Scholastic Aptitude Test (SAT) scores were above women's average scores. Referenced [16] conducted a survey on forty four (44) students and presented a list of gender differences related to games among middle school aged students: more boys (more than $80 \%$ ) played the computer game compared with girls (less than 30\%); girls prefer creative and explorative play, while boys prefer active and strategic play.

In a similar vein, reference [11] showed bases on two survey results conducted respectively on three hundred and seventeen (317) and seven hundred and ninety five (795) individuals of an average age of twenty one (21) found gender specific preferences for game features. They showed that females enjoyed games featuring meaningful social interactions but were less attracted to competitive aspects of games compared with male.

Is there a gender difference in cognitive gain when students play games in school?

As reference [29] showed the meta-analysis of various studies on gender showed that there was no significant performance difference between the two genders and concluded that both genders benefited from games cognitively. Also reference [16] found no significant gender difference in science achievement in examining the effect of games on the science achievement of fifth $\left(5^{\text {th }}\right)$ graders. The literature shows that gender plays a role in technology integration and also that there is significant differences between males and females in terms of the ability to use technology [2] and [11]. The researcher believes that things have changed now because women can go for any type of job they like and there are definitely no gender restrictions in terms of technology use in schools.

\section{Results and Discussions}

\subsection{Purpose of the Study}

The main purposes of this study were to identify principles involved in designing OBG and secondly to investigate the impact of OBG on students learning of mathematics in the JSS2 classroom and to assess gender differences among the group treated with the card game. The study therefore was design to investigate the following questions:

\subsection{Research Questions}

1. To what extent do the mean scores of students treated with card game techniques vary from students using traditional method of learning substitution?

2. What is the effect of gender composition of students treated with OBG (card game) and those treated with traditional method of learning substitution?

\subsection{Method and results}

\section{Materials}

Research shows that to learn mathematics students must, with quality instruction, master basic mathematics skills (such as arithmetic operations) in the early stages of the learning experience [18]. [2] showed that game may be an optimal teaching and learning approach to facilitate student learning of basic mathematics skills such as simple algebraic substitution and inverse operations. The study used MAT and design card game structured with TPACK framework to teach substitution against the conventional method of teaching. 40 minute's lesson on substitution was conducted for the two groups for two weeks, twice per week. The lessons were conducted in each school for 4 weeks in the whole of the two zones. After the lessons, groups were treated with MAT and IOBG, control and experimental groups respectively. In substitution card game created for the study, students play as follow:

\section{(i)The rules}

- The first player plays on the assumed card value of the playing card.

- Operation is based on face value of the last played card for subsequent play.

- The use of calculator is allowed in computing only the final result.

\section{(ii) The goal}
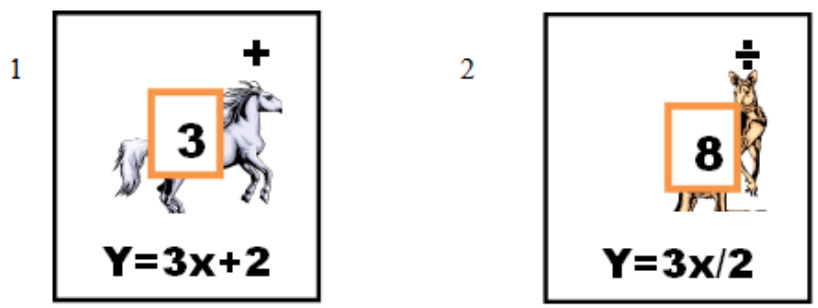

Figure 4. Game Design

The goal is to substitute the number in the middle of the card for $\mathrm{X}$ in the equation at the bottom of the card surface, to be able to have the value of the card and also use arithmetic operation at the top right edge of the card to relate with other card on the playing board. If the substitution is form correctly $\mathrm{Y}$ gives the value of the card and player uses this value and arithmetic operation in his 
card to play the card on board then he has his score. The player can move on to another card. Examples: the middle number that appears on each card represents $\mathrm{X}$, which is substituted for in the equation at the bottom of the card. To determine the value of the card, see Figures 4 below. The first card has the value of $Y=3(3)+2=11$ while the second card has the value of $\mathrm{Y}=3 * 8 / 2=12$. The arithmetic operation at the right top edge of the corner of each card is used as operating factor between two cards.

The arithmetic operation at the right top edge of the corner of each card is used as operating factor between two cards.

How to play the game

$\mathrm{X}$ equals to the bold The second playing card number on the card. has the value of his card to The number is substituted be $\mathrm{Y}=3 * 8 / 2=12$ but in place of $\mathrm{x}$ in equation met +11 on board therefore

at the bottom of the card the score will be $9+12=21$

to give score of 11 i.e.

$\mathrm{Y}=3(3)+2=11$

Third Playing Card

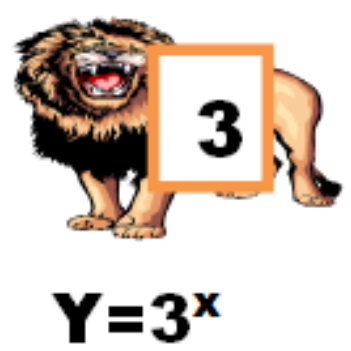

Figure 5. Third Playing Card

The 3rd playing card has the value of 27 but meets 21 on board. Using-operation on the second playing card, i.e. $21 \div 27=7 / 9$ or. 78

\subsection{Research Design}

The study is a quasi-experimental pretest-post test control group design.

\subsubsection{Participants}

The sample consists of 200 JSS 2 students selected from 20 co- educational schools within Lagos Island and Eti-Osa educational Zones of Lagos State, Nigeria. Multi stage stratified random sampling was used to avoid interclass mixed. 50\% proportionate on each zone and stratified simple random sampling technique was adopted to give non mixed schools within the zones equal chance of being taken. 100 subjects were assigned to each group; experimental (A) (card game) and control group B (traditional method). The first sets of subjects were learning in relation to game and performance, while the other set (control group) was treated with Mathematics Achievement Test (MAT) (conventional method). Lessons of 40 minutes on substitution were conducted for the two groups for two weeks, twice per week, which was conducted in each school for 4 weeks in the whole of the two zones. After the lessons the groups were treated with MAT and IOBG, control and experimental groups respectively.

\subsubsection{Instrument for Data Collection}

Mathematics Achievement Test (MAT) and OBG were constructed and used for the study. The MAT was a 30 item achievement test designed based on substitution. The reliability of MAT was established using Kuder Richardson formula 21 found to be. 86. Objects Based Game (OBG) was constructed with the reliability using Cronbach's alpha to be. 89 the two instruments have the same contents and pedagogical processes.

\subsubsection{Procedure and Sampling}

Sample: Ten subjects were chosen from each school with the same number of male and female to give the total of 200 subjects from 20 schools chosen from the two educational zones. The subjects were divided into two groups i.e. experimental and control groups. The experimental and control groups were treated with OBG and MAT respectively. Before the treatment, the subjects were given test (pre-test) related to substitution. 40 minutes Lesson on substitution was conducted for the two groups for two weeks, twice per week. This was conducted in each school for 4 weeks in the whole of the two zones. After the lessons the groups were treated with MAT and OBG, control and experimental groups respectively.

\subsection{Data Analysis}

Mean, standard deviation and analysis of ANCOVA were used to provide answers to research questions and test the significant difference that may exist.

\subsection{Results}

Research question one: To what extent do the mean scores of students treated with OBG (card game) technique inference Mathematics vary from students treated with traditional method of learning mathematics?

Table 2. Mean and Standard Deviation of the students scores in post treatment

$\begin{array}{cccc}\text { TREATMENT } & \mathrm{N} & \text { MEAN } & \text { STD DEVIATION } \\ \text { MAT } & 100 & 48.54 & 12.60 \\ \text { OBG } & 100 & 59.56 & 15.20\end{array}$

Table 2 shows that experimental group has 59.56 mean scores against control group of 48.54. This suggested that the experimental group performed better than the control group which has less mean scores.

\begin{tabular}{|c|c|c|c|c|c|}
\hline Test & SUM OF SQUARE & $\overline{D F}$ & MEAN SQUARE & $\mathrm{F}$ & SIG \\
\hline Regression & 6175.68 & 1 & 6175.68 & & \\
\hline Residual & 23966.84 & 199 & 120.44 & 12.88 & $0.013^{*}$ \\
\hline Total & 30142.52 & 200 & & & \\
\hline
\end{tabular}

* Significant @ 0.05 
Table 3 contains $F(1,199)=12.88 @ p=0.013$, this implies that the use of OBG (game) in teaching and assessing learning outcomes had significant effect on the performance of learners in mathematics. That is game (structured OBG) has impart on mathematics teaching. Table 4 also corroborated that OBG was at $F(1,193)=$
$13.00 @ p=0.00$, this shows significant of the game (OBG) against the conventional method.

\section{Research Question Two}

What is the effect of gender composition of students treated with OBG and those treated with traditional method of learning substitution?

Table 4. Analysis of Covariance (ANCOVA) of students' achievement scores

\begin{tabular}{|c|c|c|c|c|c|c|}
\hline Source Of Variation & Sum Of Square & Decree Of Freedom (Df) & Mean Square & $\mathrm{F}$ & Sig & Decision@ @ 0.05 \\
\hline Covariate (pre test) & 3187.28 & 1 & 3187.28 & 14.22 & .00 & $\mathrm{~S}$ \\
\hline Main effect & 5786.13 & 2 & 2893.07 & 12.65 & .00 & $\mathrm{~S}$ \\
\hline OBG & 2116.01 & 1 & 2116.01 & 13.09 & .00 & $\mathrm{~S}$ \\
\hline MAT & 1063.46 & 1 & 1063.46 & 8.81 & .14 & Ns \\
\hline OBG* GENDER & 390.32 & 2 & 195.16 & .85 & .35 & Ns \\
\hline MAT* GENDER & 371.94 & 2 & 185.97 & .72 & .42 & Ns \\
\hline Explained & 7129.01 & 7 & 1018.43 & & & \\
\hline Residual & 5382.81 & 193 & 27.89 & & & \\
\hline TOTAL & 12511.82 & 200 & 62.56 & & & \\
\hline
\end{tabular}

S=Significant @ 0.05; Ns = Not significant @ 0.05

Table 4 shows that $\mathrm{f}(2,193)=.85, \& .72 @ \mathrm{p}=.35$ \&. 42 both not significant. This implies that gender has no significant influence on the performance of learners in either with the used of OBG or MAT as a tool of facilitating and assessing teaching of mathematics respectively.

\subsection{Discussion}

Research has shown that the goals and rules adopted by learners during a learning task influence both their performance and their motivation [6]. Evidence from the findings of this study reveals that OBG has significant effect on students' performance in Mathematics. Group A (experimental group) had a higher mean scores than the group B that were taught the same learning content with conventional method. These findings were in support with other researches which determined that, understanding goals and rules supports student cognitive development, especially organizational skill and abstract thinking. To learn basic rudimentary Mathematics, students must, with quality instruction, master basic skills in arithmetic operations simple equations, inverse equation etc. [12]. The study shows that learners had developed mental structure required in the game to understand the underlying concepts of the game including its goals/rules, properties and conditions. Research has also shown that gaming process may be an optimal teaching and learning approach to facilitate student learning of skills in Mathematics [18]. Although these findings were a bit different from the view of [21] that assessed the efficacy of pictorial and written advance organizers to improve learners' performance. They found that pictorial organizer is more effective in enhancing students' performance than written organizer.

The results of this study also showed that gender had no significant impact on the performance between male and female students in the two groups (experimental and control groups). The findings of this study were in line with the findings of researchers who had also been interested in the differential effects of games between gender groups. While several studies have reported various gender differences in the preferences of OBG and computer game [16]. A few studies have indicated no significant differential impart of OBG between genders [29]. Till date the studies examining OBG, computer game and gender interaction are far from conclusive.

\section{References}

[1] AACTE Committee on Innovation and Technology (Ed.). (2008). Handbook of technological pedagogical content knowledge (TPCK) for educators. New York: Routledge.

[2] Agosto, D.E. (2009). Girls and Gaming: a summary of the research with implications for practice. Teacher Librarian, 31 (3), 8-14.

[3] Amory, A. (2007). Game object model version II: A theoretical framework for educational game development. Educational Technology, Research and Development, 55 (1), 51-77.

[4] Amory, A., Naicker, K., Vincent, J. \& Adams, C. (1999).The use of computer games as an educational tool: 1, identification of appropriate game type and game element. British Journal of educational Technology systems, 24, 195-205.

[5] Bloom, B. S. (1959): Taxonomy of Educational objectives, Handbook cognitive New York David. Domain, Mckay Group Inc

[6] Booker, G. (2004). Playing to win: using games for motivation and the development of mathematical thinking. In A. Rogerson (Ed.). The mathematics education into the the 21st century project: Proceedings of the international conference: The future of mathematics education. Pod Tezniami, Ciechocinek, Poland.

[7] Chandra, V. \& Lioyd, M. (2008). The methodological nettle: ICT and Student Achievement. British Journal of Educational Technology, 39, (6) 1089-98.

[8] Condie, R. \& Munro, R. (2007). The impact of ICT in schools-a landscape review; Coventry, Becta. Retrieved April 10, 2013 from http://webarchieve.nationalarchivs.gov.uk/2010110210364/publica tions.becta.org.uk.//display.cfm?resID=28221.

[9] Cox, S. (2008). A conceptual analysis of technological pedagogical content knowledge. Unpublished doctoral dissertation. Brigham Young University.

[10] Geddis, A. N. (1993). Transforming Content Knowledge: Learning to Teach about Isotopes. Science Education, 77, 575-591.

[11] Hartmann, T., \& Klimmt, C.(2010). Gender and Computer Games: Exploring females' dislikes. Journal of computer-mediated communication, 11 (4), 910-931.

[12] Hoon, T. S., Chong, T. S. \& Bintin Ngah, N. A. (2010). Effect of an interactive social game environment. British Journal of Educational Technology, 38, 3, 455-464.

[13] Hughes, J. E. (2010). Technology learning principles for preservice and in-service teacher education. Contemporary Issues in Technology and Teacher Education [Online serial], 4 (3). Retrieved from http://www.citejournal.org/vol4/iss3/general/article2.cfm

[14] Koehler, M.J., Mishra, P., \& Yahya, K. (2007). Tracing the development of teacher knowledge in a design seminar: Integrating content, pedagogy, and technology. Computers and Education, 49 (3), 740-762.

[15] Koehler, M. J., \& Mishra, P. (2010). Introducing TPCK, AACTE committee on Innovation and Technology (Ed.).The handbook of technological pedagogical content knowledge for educators. 3-29.

[16] Kinzie, M. \& Joseph, D. (2008).Gender differences in game activity preferences of middle school children: implications for educational game design. Educational Technology Research and Development, 56 (5), 643-663. 
[17] Mehlinger, H. D., \& Powers, S. M. (2002). Technology and teacher education: A guide for educators and policy makers. Boston: Houghton Mifflin Company.

[18] Miller, D. J. \& Robertson, D.P. (2010). Using a games console in the primary classroom: Effects of "Brain Training" Programme on computation and self-esteem. British Journal of Education Technology, 41, (2) 242-255.

[19] Mishra, P. \& Koehler, M.J. (2006). Technological pedagogical content knowledge: A framework for teacher knowledge. Teachers College Record, 108 (6), 1017-1054.

[20] Mishra, P., \& Koehler, M. (2007). Technological pedagogical content knowledge (TPCK): Confronting the wicked problems of teaching with technology. In C. Crawford et al. (Eds.), Proceedings of Society for Information Technology and Teacher Education International Conference 2007 (pp. 2214-2226). Chesapeake, VA: Association for the Advancement of Computers in Education.

[21] Onwioduokit, F. A \& Akinbobola, A. O. (2005). Effects of pictorial and written advance organizers on students' achievement in senior secondary school physics. JSTAN 40 (1 \& 2) 109-116.

[22] Prensky, M. (2001). Digital game-based learning. New York: McGraw-Hill.

[23] Shulman, L. S. (1986). Those who understand: Knowledge growth in teaching. Educational Researcher, 15 (2), 4-14.

[24] Shulman, L. S. (1987). Knowledge and Teaching: Foundations of the New Reform. Harvard Educational Review, 57 (1), 1-22.
[25] Shulman, L., \& Grossman, P. (1988). The intern teacher casebook. San Francisco, CA: Far West Laboratory for Educational Research and Development.

[26] Sutherland, L. M., Shin, N. \& McCall, K. L. (2010). Integrating Science inquiry, literacy, technology and universal design for learning to enhance middle school students' opportunities to learn science. Paper presented at the annual meeting of the National Association for Research in Science Teaching. Philadelphia PA

[27] Swan, K. O., \& Hofer, M. (2008). Technology and social studies. In L. S. Levstik \& C. A. Tyson (Eds.), Handbook of research in social studies education (pp. 307-326). New York: Routledge

[28] Thompson, A., \& Mishra, P. (Winter 2007-2008). Breaking news: TPCK becomes TPACK! Journal of Computing in Teacher Education, $24 \quad$ (2). $\quad$ Retrieved from http://www.iste.org/Content/NavigationMenu/Membership/SIGsSI GTETeacherEducators/JCTE/PastIssues/Volume24/Number2Wint er20072008/jcte-24-2-038-tho.pdf

[29] Vogel, J.J., Vogel, D. S., Cannon-Bowers, J., Bowers, C. A., Muse, K., \& Wright, M. (2006). Computer gaming and interactive simulations for learning: A meta-analysis. Journal of Educational computing Research, 34 (3), 229-243.

[30] Wilson, S. M., Shulman, L.S., \& Richert A. E. (1987). '150 different ways' of knowing: Representations of knowledge in teaching. In J. Calderhead (Ed.), Exploring teachers' thinking. (pp. 104-124). London: Cassell.

\section{Appendix 1}

Table A. Table of Specification

\begin{tabular}{|c|c|c|c|c|c|c|c|}
\hline Content & Knowledge & Comprehension & Application & Analysis & Synthesis & Evaluation & Total \\
\hline Simple & 1 & 2 & 2 & 1 & 1 & 1 & 8 \\
\hline \multicolumn{8}{|l|}{ equation } \\
\hline Linear & 1 & 2 & 1 & 1 & 1 & 1 & 7 \\
\hline \multicolumn{8}{|l|}{ Substitution } \\
\hline Inverse & 2 & 1 & 2 & 1 & 1 & 1 & 8 \\
\hline \multicolumn{8}{|l|}{ Operation } \\
\hline Quadratic & 2 & 1 & 1 & 1 & 1 & 1 & 7 \\
\hline \multicolumn{8}{|l|}{ Substitution } \\
\hline Total & 6 & 6 & 6 & 4 & 4 & 4 & 30 \\
\hline
\end{tabular}

Note: Activities at Various Cognitive Levels of Learning (LoL)

Bloom's taxonomy of learning objectives are used to define how well a skill or competence is learned or mastered. Each content on the table was calculated by the cognitive Levels of Learning (LoL). To determine allocation for each LoL against each content, the number of LoL allocated to each content depends on the interest of the item developer on what to be tested among the LoL. In this case (Table A), 20\% was allocated to the first $3 \mathrm{LoL}$, while the last 3 were allocated with $13.3 \%$ each. For examples:

\begin{tabular}{|c|c|}
\hline LoL & Number of Allocation \\
\hline Knowledge & $20 / 100$ X 30/1 =6 \\
\hline Synthesis & $13.3 / 100$ X 30/1 = 4 \\
\hline
\end{tabular}

To obtain allocation for each content against LoL, the researcher distributed the total number of each LoL on each content, based on the interest. For example, knowledge has the total of 6 and is being distributed to content thus: simple equation $=1$, linear substitution $=1$, inverse operation $=2$ and quadratic substitution $=2$.

A brief summary of the activities associated with each level is given below.

\section{Knowledge (Information)}

1. At Knowledge Level of Learning a student can define terms.

2. How do I know I have reached this level?

I can recall information about the subject, topic, competency, or competency area; I can recall the appropriate material at the appropriate time. I have been exposed to and have received the information about the subject; thus, I can respond to questions, perform relevant tasks, etc.

\section{Comprehension (Understanding)}

1. At Comprehension Level of Learning a student can work assigned problems and can example what they did

2. How do I know I have reached this level?

I comprehend or understand the subject, topic, competency, or competency area; I use ideas associated with the subject without relating them to other ideas or subjects. I may not yet completely understand the subject. When others are discussing this subject, I can follow and understand the discussion. This level requires Knowledge.

\section{Application (Independent Problem Solving)}

1. At Application Level of Learning a student recognizes what methods to used and then used the methods to solve problems

2. How do I know I have reached this level?

I can recognize the need to use an idea, concept, principle, theory, or general solution methods (techniques and procedures) without being told and without any specific or immediate context or cues. For example, I do 
not need to locate a similar example in a textbook, nor do I need to know that an assignment is for a particular course in order to recognize the need to use a particular idea, etc. I know and comprehend these ideas, concepts, principles, theories, or general solution methods (techniques and procedures and I can apply them to new situations. I also have the ability to recognize when a certain task or project is beyond my current competency. This level requires Knowledge and Comprehension.

\section{Analysis (Logical Order, Components)}

1. At Analysis Level of Learning a student can explain why the solution process works.

2. How do I know I have reached this level?

I can explain why. I can methodically examine ideas, concepts, principles, theories, general solution methods (techniques and procedures), reports, etc. and separate these into their component parts or basic elements. I can use the results of this examination to clarify the organization of the whole or to gain a global view. This level requires Knowledge and Comprehension Levels of Learning; Application is not required.

\section{Synthesis (Create)}

1. At Synthesis Level of learning a student can combine the part of a process in new and useful ways.

2. How do I know I have reached this level?

I have the ability to assemble parts and elements into a unified organization or whole that requires original or creative thinking. I recognize new problems and develop new tools to solve them. I create my own plans, models, hypotheses, etc. for constructing solutions to problems. This Level of Learning requires Knowledge, Comprehension, Application and Analysis Levels of Learning.

\section{Evaluation (Appreciation)}

1. At Evaluation Level of learning a student can create a variety of ways to solve the problem and then, based on established criteria, select the solution method best suited for the problem.

2. How do I know I have reached this level?

I have the ability to judge and appreciate the value of ideas, concepts, principles, theories, or general solution methods (techniques and procedures) using appropriate criteria. This level requires Knowledge, Comprehension, Application, Analysis, and Synthesis Levels of Learning. 